УДК 911.3

DOI 10.18101/2587-7143-2019-1-55-63

\title{
ТРАНСПОРТНО-ГЕОГРАФИЧЕСКОЕ ПОЗИЦИОНИРОВАНИЕ РЕСПУБЛИКИ БУРЯТИЯ ${ }^{1}$
}

\section{Б. Л. Раднаев}

\section{(C) Раднаев Баир Лубссанович}

доктор географических наук, профессор

Бурятский государственный университет,

Байкальский институт природопользования СО РАН

Россия, 670000, г.Улан-Удэ, ул. Смолина, 24а.

Россия 670047, г. Улан-Удэ, ул. Сахьяновой, 6

\section{Для цитирования:}

Раднаев Б. Л. Транспортно-географическое позиционирование Республики Бурятия // Вестник Бурятского государственного университета. Биология, география. 2019. № 1. C. 55-63.

В статье рассмотрен комплекс вопросов, связанных с реализацией стратегии развития транспорта в Азиатской части России с учетом требований ускорения развития экономики страны в условиях глобализации. Раскрыты особенности развития транспортного комплекса Республики Бурятия, отдельных его видов, формирование транспортно-промышленных узлов и других объектов кластерного типа как основы перехода страны на этап прорывного и инновационного развития экономики.

1 Редколлегия представляет одну из работ Б. Л. Раднаева (1942-2012). Данный материал является частью коллективной монографии «Стратегические направления долгосрочного развития транспортной инфраструктуры Сибири и Дальнего Востока. Горизонт-2030» под научной редакцией С. Н. Васильева, А. П. Хоменко, С. С. Гончаренко и др., изданной в 2009 г. в г. Иркутск, в издательстве ИрГУПС (Раднаев Б. Л. Транспортногеографическое позиционирование Республики Бурятия (Раздел 3.5 - стр. 308-312)).

В статье выполнен анализ транспортной системы Республики Бурятия в контексте международного сотрудничества. Отражены основные актуальные вопросы развития транспорта в Республике Бурятия, часть из которых, к сожалению, по-прежнему актуальна в настоящее время. На основе анализа ситуации Б. Л. Раднаевым предложены мероприятия и механизмы по совершенствованию транспортной инфраструктуры.

В настоящее время статью профессора можно признать концептуальной, с большим количеством прогнозных данных. Особенно актуально на фоне развития восточного вектора развития страны, создания ТРК «Байкальская гавань» и ежегодного роста туристского потока, введения безвизового режима с Монголией, начала реализации крупных проектов по созданию международных экономических коридоров. Идеи о создании МТЛЦ на территории Республики Бурятия имеют шансы для осуществления в рамках реализации крупных международных проектов по созданию экономических коридоров по маршрутам Шелкового и Чайного пути. 
Ключевые слова: Республика Бурятия, транспортно-географическое положение, транспортная система

В условиях вхождения Российской Федерации в глобализирующий мир транспортно-географическое позиционирование ее регионов становится важнейшим условием совершенствования пространственной социальноэкономической структуры, повышения экономической эффективности хозяйства, выработки геополитической стратегии страны. Для этого необходимо выбрать «полюсы» или регионы роста, которыми могут стать стратегические районы, расположенные в приграничных территориях. При определенных транспортнокоммуникационных условиях приграничные регионы смогут обеспечить продвижение геополитических интересов государства, взаимодополнить экономическую структуру соседних государств, установить взаимные связи в гуманитарной и культурной сфере, активизировать инвестиционные потоки, способствовать включению сопредельных районов и стран в региональную и международную систему территориального разделения труда (Колосов, 2004). Эти регионы должны служить плацдармом концентрации усилий государства на ключевых направлениях, чтобы они заняли достойную конкурентную позицию в мировом экономическом и геополитическом пространстве. К таким территориям, без сомнения относится Байкальский регион в целом и Республика Бурятия, в частности, расположенные на границе с Монголией и Китаем, имеющих надежные транспортно-коммуникационные связи с этими странами (Гончаренко, 2003).

В этом плане Республика Бурятия в составе Байкальского региона имеет все потенциальные возможности превращения в стратегически важную территорию России. Это обусловлено географическим, геополитическим, транспортным положением региона, сравнительно крупным, концентрированным вдоль Транссиба ресурсным, экономическим, особым этнокультурным демографическим потенциалом. Объявление озера Байкал частью Мирового природного наследия привлекло внимание всех жителей Земли, так как главные богатство Байкала - это хранилище $20 \%$ запасов чистой пресной воды планеты. Воспроизводство и восполнение этой воды происходит на территории бассейна озера Байкал, находящегося в пределах Бурятии, Иркутской области, Забайкальского края и Монголии. Сохранение в чистоте байкальской воды для человечества становится глобальной проблемой, когда населения, в частности, Китая, в ближайшее десятилетие столкнется с проблемой дефицита пресной воды. Между тем транспортно-коммуникационные условия бассейна озера играют не малую роль в решении экологических проблем Байкала, ибо только при совершенной транспортной системе можно решить вопросы рационального природопользования.

Особенность транспортной системы и транспортно-географического положения Байкальского региона заключается в том, что отсюда ветром расходятся все наземные пути сообщения и магистральные линии связи, высоковольтные линии электропередач на восток и северо-восток России, в страны Восточной и Центральной Азии (Раднаев, 1996). Намечена прокладка в этом же направлении магистральных нефте- и газопроводов. Возможность транспорта Байкальского 
Раднаев Б. Л. Транспортно-географическое позиционирование Республики Бурятия

региона включиться в мировые транспортные сети усиливается в связи созданием в будущем сухопутного транспортного коридора Западная Европа - Восточная Азия. Регион расположен фактически в середине Российского участка, отсюда уходят пути сообщения в Монголию, районы Ближнего и Дальнего Севера России. Интенсивное использование данного фактора для совершенствования местной транспортно-коммуникационной сети и на этой основе проведение диверсификация структуры экономики становится задачей номер один для региона (Раднаев, 2003).

Пока Республика Бурятия по обеспеченности железнодорожными путями, автомобильными дорогами с твердым покрытием (4,7 км, 19,4 км на 1000 кв. км территории) отстает от средних российских показателей в два раза, несмотря на то, что по её территории проходят три федеральные автодороги. Железные дороги Республики Бурятия представлены сетью общего пользования и подъездными путями предприятий. С запада на восток проходит на севере БАМ, на юге Транссибирская железнодорожная магистраль. От Улан-Удэ в южном направлении проходит железнодорожная линия в Монголию, Китай. Эта однопутная железнодорожная линия на тепловозной тяге требует срочной реконструкции, основные фонды на монгольском участке изношены на 60-70\%. Улан-Баторская железная дорога, эксплуатирующая эту линию по территории Монголии, является совместным российско-монгольским предприятием. Поэтому Россия ответственная за состояние этой дороги. Пограничная станция Наушки является одним из ведущих железнодорожных переходов при перевозках грузов и пассажиров в Монголию и Китай. Особое значение имеет в целях охраны Байкала реконструкция и строительство современной автодороги вдоль восточного побережья озера. Сообщение водным транспортом осуществляется по озеру Байкал и рекам Селенге, Баргузин. На реке Селенга расположен речной порт Улан-Удэ. Водный транспорт в целом находится в упадке. Основной объем работы связан с перевозками грузов: лесных, песчано-гравийных и нефтепродуктов. Объем пассажирских перевозок очень мал. Надежда на его подъем имеется в случае развития туристско-рекреационной деятельности на Байкале.

Протяженность местных воздушных линий составляет 3719 км. Дальними перевозками занимаются авиакомпании других регионов. Состояние здания аэропорта г. Улан-Удэ не соответствует международным стандартам. Аэропорт не рассчитан на прием большого количества пассажиров, отсутствует сообщение со многими регионами России и странами АТР. Все это требует изменений государственной политики развития воздушного транспорта Бурятии.

Стратегически важное значение имеют природные ресурсы Республики Бурятия. Ее недра содержат 48\% балансовых запасов цинка России, 24\% свинца, $37 \%$ - молибдена, 27\% - вольфрама, 16\% - плавикового шпата и 15\% - хризотил-асбеста. Одними из основных восполняемых природных ресурсов являются лесные. Общая площадь лесного фонда составляет 27,2 млн. га, их них покрытая лесом - 20,3 млн. га. Общий запас древесины составляет 2244 млн. куб. м. Обилие прибайкальской флоры - основа для традиционной восточной медицины. Байкал и окружающую территорию населяют 2500 различных видов фауны, из которых 250 видов эндемичны. 
Промышленность Республики Бурятия представлена следующими основными отраслями: электроэнергетикой, производством авиационной техники, ремонтом железнодорожного подвижного состава, добычей золота, угля, производством пиломатериалов и целлюлозы, картона, металлоконструкций, продуктов переработки мяса, алкогольной продукции, макаронных изделий, электронных и оптических приборов. В 2005 г. промышленность практически вышла на дореформенный уровень: индекс физического объема составил 97,6\% к уровню 1990 г. В Бурятии быстро развивается сфера услуг. Если в среднем по России в 2004 г. удельный вес отраслей, производящих услуги, был на уровне 49,9\%, а в Сибирском федеральном округе - 48,1\%, то в Республике Бурятия он составил $51,2 \%$. По числу работающих, имеющих высшее образование (на 1000 занятых - 243), Республика Бурятия в Сибирском федеральном округе уступает только Томской области - 255 и опережает все другие субъекты Федерации.

Существующая экономическая структура Республики Бурятия требует пересмотра в рамках стратегического подхода в сторону формирования инфраструктурных ресурсоперерабатывающих, рекреационно-туристских кластеров, а также в производстве экологически чистых продуктов, и в том числе в будущем производстве и поставке из Байкала питьевой воды в страны Восточной Азии. По данным ООН, дефицит пресной воды в мире оценивается в 230 млрд. $\mathrm{M}^{3}$ в год. В 2005 г. оборот рынка пресной воды составил уже более 400 млрд. долл. Ежегодно продается свыше 100 млрд. л. бутилированной питьевой воды. По экспертным данным доходы от торговли водой сопоставимы с доходами крупных нефтяных компаний. Вместе с тем разработку проектов такого характера следует проводить в контексте более общих стратегий развития всего Байкальского региона и с учетом формирования новых связей со странами АТР, Монголией и Китаем.

Для формирования указанных кластеров Бурятия должна выдержать конкуренцию со своими соседями. Она как транзитная или буферная территория должна предпринять меры, чтобы проходящие материальные и другие потоки каким-то образом «оседали, задерживались или перерабатывались» на ее территории для формирования добавленной стоимости. По минерально-сырьевому и лесному комплексам конкурентами являются Иркутская область и Забайкальский край, по транзитному фактору - Забайкальский край, по Байкальскому фактору Иркутская область. Изменение подобной позиционной ситуации возможно только в случае формирования в г. Улан-Удэ крупного транспортно-коммуникационного инфраструктурного кластера.

При условии принятия такой стратегии развития Бурятия сможет стать «транспортно-коммуникационными воротами» России в страны Центральной, Восточной и Юго-Восточной Азии. У формируемого международного транспортного коридора должно быть соответствующее внутренне содержание в виде региональных инфраструктур, иначе он превратится в простой транзитный коридор (Андерсон, 2001). Ими должны стать региональные транспортнологистические центры, формируемые в транспортных узлах. На пути этого коридора на территории Байкальского региона находятся крупные опорные транспортные узлы - Иркутск, Улан-Удэ, Чита. Именно в Байкальском регионе необходимо создать координационные, логистические центры по управлению и перераспределению 
Раднаев Б. Л. Транспортно-географическое позиционирование Республики Бурятия

материальными и информационными потоками, по продвижению и реализации геополитических и экономических интересов России в странах Восточной Азии, а также для создания условий для представления интересов государств АТР в Сибири, сохраняя стратегические интересы России (Геополитические..., 2001).

К внутренним условиям формирования центра транспортно-коммуникационных услуг международного значения относятся наличие в городах Иркутск, Улан-Удэ, Чита резервного потенциала транспортной инфраструктуры, способного стать материальной базой данного центра. Во всех трех городах имеются аэропорты, которые могут принимать все типы летательных аппаратов, ремонтные предприятия транспортной техники, дорожно-строительные организации и возможности для логистических операций с грузами. Байкальский центр транспортнокоммуникационных услуг должен иметь терминальный комплекс международного значения, в его составе должны функционировать транспортно-экспедиторские фирмы по мультимодальным комбинированным перевозкам с лизингом и арендой транспортных средств, страхованием грузов, формированием системы сервисного обслуживания пассажиров и транспортных средств. Данный центр должен быть составной частью будущего Байкальского выставочно-делового центра Евразии, предложенного нами организовать в г. Улан-Удэ.

Офисная часть Байкальского центра транспортно-коммуникационных услуг может быть размещена в Улан-Удэ, расположенном в середине Байкальской природной территории, имеющей потенциальные инфраструктурные, территориальные резервы и кадровый потенциал по обслуживанию транспортнокоммуникационных систем. Поскольку Улан-Удэ расположен на перекрестке путей сообщения, магистральных линий связи, идущих на запад, на восток, в Монголию, то логично создание здесь логистического центра, одновременно как «полюса роста» современных технологий в данном регионе. Города Иркутск и Чита, находящиеся в западной и восточной части Байкальской природной территории, менее уязвимы по экологическим параметрам и могут стать контактными центрами промышленного развития.

Предпосылки для такого подхода есть. Уже сейчас транспортный узел УланУдэ является крупным транспортным комплексом со всей инфраструктурой (локомотиво-вагоноремонтный завод, аэропорт с искусственной взлетнопосадочной полосой, авиационный завод с ВПП для приема всех типов летательных аппаратов, речной порт, ремонтные предприятия автомобильного транспорта). Улан-Удэ - узел магистральных линий связи, способствующий созданию здесь логистического центра для управления товарными потоками. Здесь имеются все материально-технические условия для хранения, сортировки, распределения товаров и дальнейшего продвижения их потребителям разными видами транспорта. Все это объективно предопределяет размещение терминального комплекса международного значения, транспортно-экспедиционных компаний и логистических фирм - операторов интермодальных комбинированных перевозок, с лизингом и арендой транспортных средств, страхованием грузов, созданием системы сервисного обслуживания клиентуры и транспортных средств. В местных учебных заведениях можно готовить кадровый потенциал. 
Создание в Республике Бурятия в районе г. Улан-Удэ МТЛЦ (международного транспортно-логистического центра) и мультмодального терминального комплекса, выполняющих функции логистического распределительного сервисного и делового центра, усилит геополитическую позицию России в Монголии, в Китае и других странах Восточной и Юго-Восточной Азии, а для Байкальского региона это станет источником социально-экономического развития в условиях экологической регламентации хозяйственной деятельности. Производство услуг - экологически чистое мероприятие. Тем самым начнут реализовываться положения Закона РФ об охране озера Байкал(Раднаев, 2003).

В перспективе Байкальский центр транспортно-коммуникационных услуг должен формироваться как составная часть и опорный центр межконтинентального транспортно-коммуникационного коридора Европа-Азия. Для этого должен быть создан соответствующий транспортный каркас региона. Для формирования такого каркаса необходимо реализовать ряд среднесрочных и долгосрочных мероприятий. Принципиально новую возможность для развития Бурятии дает запланированная к строительству железнодорожная линия, соединяющая БАМ и Транссиб по маршруту Могзон - Озерное - Уоян. Участок Могзон - Озерное (161 км), на котором возобновится строительство (строительные работы были прекращены в 1995 году), необходим в связи с освоением Озерного месторождения полиметаллов. Прогнозируемый объем перевозок по этой дороге к 2012 г. может составить 7 млн.т. Другим важным объектом является завершение формирования Кругобайкальской автомагистрали по маршруту Иркутск -Усть-Кут - Северобайкальск - Уоян Курумкан - Баргузин - Кабанск - Байкальск - Иркутск, где необходимо построить или реконструировать отдельные участки. Например, на территории Бурятии построить участок Курумкан-Уоян. Не требует отлагательства строительство автомагистрали вдоль БАМа, уложить второй путь и электрифицировать линию Улан-Удэ - Наушки - Улан-Батор. Организация круизного пассажирского судоходства по озеру Байкал также представляется необходимой. Без него трудно представляется нормальное функционирование здесь туристско-рекреационной зоны международного значения.

Все вышеизложенное объективно предопределяет организацию в центре пересечения международных транспортных коридоров «Европа - Азия» и кроссполярных воздушных маршрутов «Север-Юг» Байкальского делового центра международного сотрудничества, для которого рекомендуется создать транспортно-логистический центр с мультимодальным терминальным комплексом, а также сервисное и коммерческо-деловое обслуживание. Для реализации этих идей необходимо мобилизовать все имеющиеся внешние и внутренние ресурсы, привлечь новые формы глобальной и трансрегиональной интеграции, представленные такими организационно-функциональными структурами интегрированного взаимодействия, как международные сетевые организации, транснациональные корпорации и кластеры, обеспечивающие максимальный синергетический эффект и повышение конкурентоспособности участников интегрированных образований.

Участок Транссибирской магистрали, проходящей через Бурятию, и линия УланУдэ - Наушки с Улан-Баторской железной дорогой станет важнейшим сегментом, 
Раднаев Б. Л. Транспортно-географическое позиционирование Республики Бурятия

который свяжет Россию с Внутренней Азией и юго-восточными портами Китая. Центром или зоной приграничного сотрудничества в Бурятии может стать город Кяхта со станцией Наушки, прилегающий к Кяхте на территории Монголии, поселком Алтанбулаг и городом Сухэ-Батор. Монголия в 2002 г. создала в районе Алтанбулага зону свободной торговли площадью в 500 га. Поэтому, «опорными точками роста», «экономическим коридором» развития на территории Республики Бурятия может стать линия, проходящая по городам Улан-Удэ - Гусиноозерск Кяхта — с продолжением в Монголии (Балжанням, 2009).

По мере формирования в Улан-Удэнском транспортном узле крупного МТЛЦ международного уровня появится возможность строительства многофункционального МТЛЦ в районе железнодорожной станции Наушки и торгового центра в Кяхте с созданием центров оптовой торговли и дистрибьюции с блоками сервисного и делового обслуживания (Мещанинов, 2009), мультимодальным терминалом, центром приграничного сотрудничества и формирование свободной таможенной зоны. По мере расширения торговли и роста товарных потоков в направлении Улан-Удэ - Кяхта = Улан-Батор и далее в Китай с выходом к морю, а далее к странам Азии и Европы, может сформироваться южное логистическое направление Республики Бурятия, в состав которого войдут небольшие по мощности терминальные комплексы в г. Гусиноозерск и в центрах административных районов юга Бурятии.

Необходимо предусмотреть создание МТЛЦ в зоне БАМа и основным пунктом размещения данного центра будет г. Северобайкальск, который будет координировать такие будущие транспортные узлы как Таксимо и Уоян. В будущем соединение по территории Бурятии Транссиба и БАМа и расширение южного (монголо-китайского) направления откроет новые перспективы для дальнейшего совершенствования транспортно-логистической инфраструктуры, увеличения туристских потоков на Байкал. Для обслуживания прибывающий на территорию Бурятии туристов (планируется до 1 млн. чел. в год) потребуется строительство мультимодального пассажирского транспортно-логистического центра с полной реконструкцией аэропорта в Улан-Удэ и восстановлением аэропортов в Прибайкалье, а также реконструкция пассажирских, железнодорожных, автомобильных вокзалов.

ДляреализациивсегоэтогоуБурятииимеетсяособоепозиционноепреимущество. Географическое и геополитическое положение,этнокультурные особенности проживающего в Бурятии населения предопределили здесь сплав восточных и западных культур, мирное сосуществование здесь двух мировых религий (христианства и буддизма). Этот фактор успешно использовала дореволюционная Россия и советская власть в начале XX в. для продвижения и укрепления своих интересов в Монголии и Китае, что, к сожалению, слабо использует современная Россия. В настоящее время эти отношения и этнокультурные особенности могут сделать Бурятию не транзитным коридором, а воротами, где встречаются несколько различных культур: европейская, русская, китайская, бурятская, тибетская и монгольская. В экономическом плане это означает, что туристско-рекреационное и транспортно-логистическое позиционирование Бурятии станут «полюсами роста» в глобальном социально-экономическом пространстве. 
Отсюда вытекают стратегические возможности и миссия Байкальских регионов, расположенных в приграничных территориях. Они, включая Бурятию, призваны обеспечить продвижение геополитических интересов государства, взаимодополнять экономику соседних стран при условии их дружественных отношений с Россией, продвигать перспективные взаимные интересы в гуманитарной сфере, сопровождать и анализировать инвестиционные потоки. Эти регионы должны служить плацдармом концентрации усилий государства на ключевых территориях российского пространства (Цыганков, 2003).

Решение этих задач связано с необходимостью взаимного согласования программ социально-экономического развития с соседними субъектами федерации, заинтересованностью федеральных органов исполнительной власти по формированию соответствующей региональной политики, крупных государственных монополий и потенциальных инвесторов.

В конечном итоге все это будет способствовать превращению Байкальской природной территории в стратегический регион для всей Евразии и выступить в роли проводника геополитических интересов России в страны АТР.

\section{Литература}

1. Андерсон А. Ворота в глобальную экономику. М.: ФАЗИС, 2001. 440 с.

2. Балжанням Д., Якобсон А.Я. Экономико-географический потенциал монголороссийских взаимосвязей. Иркутск: Изд-во Ин-та географии им. В.Б. Сочавы СО РАН, 2009. 175 c.

3. Геополитические и социально-экономические проблемы создания международных транзитных коридоров. Иркутск: Минтранс РФ, 2003. Т.1. 387 с., Т.2. 605 с.

4. Гончаренко С.С. Транспортная стратегия в Сибири и на Дальнем Востоке как условие ускоренного роста национальной безопасности и укрепление геополитической позиций России. // Геополитические и социально-экономические проблемы создания международных транзитных коридоров. Т.1. Иркутск, 2003. 387 с.

5. Колосов В.А. Новое российское пограничье: Основные особенности и перспективы развития приграничного сотрудничества//Проблемы приграничных регионов России/ Под ред. Ю.Г. Липеца. М.: ИГ РАН, 2004. С. 5-11.

6. Мещанинов М.Б. Регионы России в торгово-экономическом сотрудничестве с Монголией. М.: ЛИБРОКОМ, 2009. 164c.

7. Раднаев Б.Л. Транспорт Востока Сибири в новой социально-экономической и геополитической ситуации. Новосибирск: Издво СО РАН, 1996. 128 с.

8. Раднаев Б. Л. Формирование Байкальского делового центра Евразии (транспортный аспект) // Транспортная стратегия России. Материалы научнопрактической конференции 1213 мая 2003г., Новосибирск, 2003.

9. Цыганков А. П. Что для нас Евразия? Пять стратегий российского освоения пространства после распада СССР//Вопросы философии. 2003. № 10. С. 3-17. 
Раднаев Б. Л. Транспортно-географическое позиционирование Республики Бурятия

\section{TRANSPORT AND GEOGRAPHICAL POSITIONING OF THE REPUBLIC OF BURYATIA}

\section{Bair. L. Radnaev}

Dr. Sci. (Geogr.), professor

Baikal Institute of Nature Management SB RAS,

Russia, Ulan-Ude 670047, Sakhyanova st., 8

Buryat state university

24a, Smolina str., Ulan-Ude, 670000, Russia

This article discusses a set of issues related to the implementation of the strategy of transport development in the Asian part of Russia, taking into account the requirements of accelerating the development of the country's economy in the context of globalization. The features of the development of the transport complex of the Republic of Buryatia, its individual types, the formation of transport and industrial hubs and other objects of the cluster type as the basis for the country's transition to the stage of breakthrough and innovative development of the economy.

Key words: Republic of Buryatia, transport and geographical location, transport system 